\title{
Association of the neoadjuvant chemotherapy cycle with survival outcomes in patients with locoregionally advanced nasopharyngeal carcinoma: a propensity-matched analysis
}

\author{
Wang Fangzheng ${ }^{1,2,3, *}$, Jiang Chuner ${ }^{4, *}$, Ye Zhimin ${ }^{1,2}$, Sun Quanquan ${ }^{1,2}$, Liu Tongxin ${ }^{1,2}$, \\ Xu Min ${ }^{5}$, Wu Peng ${ }^{6}$, Long Bin ${ }^{7}$, Masoto Sakamoto ${ }^{3}$, Wang Yuezhen ${ }^{1,2}$, Yan Fengqin ${ }^{1,2}$, \\ Fu Zhenfu ${ }^{1,2}$ and Jiang Yangming ${ }^{8}$ \\ ${ }^{1}$ Department of Radiation Oncology, Zhejiang Cancer Hospital, Zhejiang Hangzhou 310022, People's Republic of China \\ ${ }^{2}$ Zhejiang Key Laboratory of Radiation Oncology, Zhejiang Hangzhou 310022, People's Republic of China \\ ${ }^{3}$ Department of Radiology, Japanese Red Cross Fukui Hospital, Fukui 918-8501, Japan \\ ${ }^{4}$ Department of Breast Tumor Surgery, Zhejiang Cancer Hospital, Zhejiang Hangzhou 310022, People's Republic of China \\ ${ }^{5}$ Department of Physics, Zhejiang Cancer Hospital, Zhejiang Hangzhou 310022, People's Republic of China \\ ${ }^{6}$ Department of Pathology, Zhejiang Cancer Hospital, Zhejiang Hangzhou 310022, People's Republic of China \\ ${ }^{7}$ Department of Nuclear Medicine, Zhejiang Cancer Hospital, Zhejiang Hangzhou 310022, People's Republic of China \\ ${ }^{8}$ Department of Didital Earth, Institute of Remote Sensing and Didital Earth, CAS, Beijing 100101, People's Republic of China \\ * These authors have contributed equally to this work \\ Correspondence to: Jiang Yangming, email: jym_wm@126.com \\ Wang Fangzheng, email: wangfz76@126.com \\ Keywords: nasopharyngeal carcinoma, neoadjuvant chemotherapy, cycle, survival outcomes, prognosis \\ Received: July 18, $2017 \quad$ Accepted: September 21, $2017 \quad$ Published: October 06, 2017 \\ Copyright: Fangzheng et al. This is an open-access article distributed under the terms of the Creative Commons Attribution License \\ 3.0 (CC BY 3.0), which permits unrestricted use, distribution, and reproduction in any medium, provided the original author and \\ source are credited.
}

\section{ABSTRACT}

Neoadjuvant chemotherapy (NAC) is widely used to treat locoregionally advanced nasopharyngeal carcinoma (NPC). To determine the optimal number of NAC cycles, we assessed the effect of NAC cycle on survival outcomes of locoregionally advanced NPC patients receiving NAC before concurrent chemotherapy and intensitymodulated radiotherapy. Clinical data from 1,188 non-metastatic NPC patients were retrospectively reviewed. All received $\geq 2$ cycles of NAC added to concurrent chemoradiotherapy. Propensity score matching (PSM) was used to identify paired patients according to various covariates. In total, 297 pairs were selected. After a median follow-up time of $\mathbf{5 7}$ months (range: $\mathbf{7}$ to 104 months), the 5-year locoregional relapse-free survival, distant metastasis-free survival (DMFS), progression-free survival (PFS), and overall survival rates in patients treated with 2 cycles vs. 3 to 4 cycles of NAC were $91.3 \%$ vs. $87.2 \%(P=0.149), 93.3 \%$ vs. $88.5 \%(P=0.043), 88.7 \%$ vs. $81.7 \%(P=0.037)$, and $94.0 \%$ vs. $92.6 \%(P=0.266)$, respectively. On multivariate analysis, 2 cycles of NAC were associated with improved DMFS (hazard ratio, 0.499; $P=0.038$ ) and PFS (hazard ratio, $0.585 ; P=0.049$ ). NAC cycle was an independent prognosticator of DMFS and PFS in univariate and multivariate analyses. Thus, 2 cycles of NAC appear sufficient, as additional cycles were not associated with added survival benefit for locoregionally advanced NPC.

\section{INTRODUCTION}

The incidence of nasopharyngeal carcinoma (NPC) is 15 to 50 cases per 100,000 annually in Southern China,
Singapore, and Malaysia that vary with age, ethnicity, and geographical origin [1]. Radiotherapy (RT) is the standard treatment for NPC because of the anatomical location and the high radiosensitivity. Patients with locoregionally 
advanced NPC at diagnosis account for $60 \%$ to $70 \%$ of all NPC patients [2]. Intensity-modulated radiation therapy (IMRT) has been used to improve locoregional control but provides little benefit for survival outcome and prevention of distant failure [3, 4]. According to meta-analyses of randomized studies, combination RT and chemotherapy reduces the risk of mortality by $18 \%$ and increases 5 -year survival by $4 \%$ to $6 \%$ [5]. Concurrent chemoradiotherapy (CCRT) with or without adjuvant chemotherapy, which provides a benefit in overall survival (OS), has become the standard treatment for locoregionally advanced NPC, although with acute toxicities [6-8]. A meta-analysis showed that compared with CCRT alone, addition of neoadjuvant chemotherapy (NAC) to CCRT reduces distant failure in locoregionally advanced NPC patients $[9,10]$, and another meta-analysis confirmed that NAC followed by CCRT improved progression-free survival (PFS) and OS [11]. However, the efficacy of the additional NAC to CCRT in patients with locoregionally advanced NPC remains controversial [12-14]. Sun et al. reported that 3 cycles of docetaxel, cisplatin, 5-fluorouracil-based induction chemotherapy (TPF IC) before CCRT improve survival outcomes, with 3-year OS of $92 \%$, 3-year failurefree survival (FFS) of $80 \%$, and 3-year distant metastasesfree survival (DMFS) of $90 \%$ [15]. In the study by Kong et al. [16] of the TPF IC regimen in the treatment of locoregionally advanced NPC, 3-year OS, PFS, DMFS, and locoregional free-survival (LRFS) were 94.8\%, $78.2 \%, 90.5 \%$, and $93.9 \%$, respectively [16]. Considering these results, addition of NAC to CCRT is a promising option for locoregionally advanced NPC patients in the era of IMRT.

However, the number of cycles of NAC that should be recommended for these patients is unclear. In previous studies [12-17], NPC patients received 2, 3, and even 4 cycles of NAC. More cycles of NAC delay IMRT delivery and prolong the wait time of IMRT. Unfortunately, longer IMRT wait time is associated with poor survival outcomes of NPC patients $[18,19]$. Therefore, whether a threshold of NAC cycles exists, beyond which an impact on the survival of NPC patients is seen, needs further study. On the basis of this hypothesis, we performed a retrospective study to compare long-term survival outcomes of adding 2 cycles vs. 3 to 4 cycles of NAC to CCRT in locoregionally advanced NPC patients. To avoid the interference of covariates, we used the propensity score matching (PSM) methods to select paired patients [20].

\section{RESULTS}

\section{Patient characteristics}

The clinical data of 1,188 newly diagnosed locoregionally advanced NPC patients, who were initially treated with NAC followed by CCRT, were collected and retrospectively reviewed. From the original data, 297 pairs were selected by PSM. Basic characteristics of all patients are summarized in Table 1. For the selected subjects, the median age was 50 years (range, 18 to 77 years), and the ratio of males to females was 1.94:1 (392:202). There were no statistically significant differences in age, gender, stage, and treatment factors between 2 cycles and 3 to 4 cycles of NAC.

\section{Survival outcomes}

With the median follow-up duration of 57 months (range, 7 to 104 months), the estimated 5-year locoregional relapse-free survival (LR-RFS), DMFS, PFS, and OS rates were $89.3 \%, 90.9 \%, 85.1 \%$, and $93.3 \%$, respectively (Figure 1).

The 5-year DMFS rate was higher for patients treated with 2 cycles of NAC than for those treated with 3 to 4 cycles of NAC $(93.3 \%$ vs. $88.5 \%$, respectively; $P=0.043$ ) (Figure 2B). An improvement occurred in the 5-year PFS rate $(88.7 \%$ vs. $81.7 \%$, respectively; $P=$ 0.037 ) (Figure 2C) in patients who received 2 cycles of NAC compared with those who received more cycles of NAC. A statistically significant difference in LR-RFS and OS was not found between the two groups (5-year LRRFS: $91.3 \%$ vs. $87.2 \%$, respectively, $P=0.149$ [Figure 2A] and 5-year OS: $94.0 \%$ vs. $92.6 \%$, respectively, $P=$ 0.266 [Figure 2D]).

\section{Failure patterns}

Treatment failure occurred in 88 patients $(14.8 \%)$ by the last follow-up. In the 2-cycles group, 35 patients $(11.8 \%)$ experienced "any" failure (locoregional relapse occurred in 14 patients, locoregional relapse and distant failure occurred in 12 patient, and distant metastases occurred in 9 patients), and 53 patients $(17.8 \%)$ in the 3 to 4 cycles group experienced "any" failure (locoregional relapse occurred in 18 patients and locoregional relapse and distant failure occurred in 17 patients, and distant failure alone occurred in 17 patients). Patterns of treatment failure in NPC patients are listed in Table 2. Median time to failure in patients receiving 2 cycles of NAC versus 3 to 4 cycles of NAC was 22 months (range, 6 to 99 months) versus 26 months (range, 6 to 65 months), respectively.

\section{Identification of prognostic factors}

The common potential prognostic factors included patient age, patient sex, clinical stage, adjusted tumor (T) and lymph node (N) stage, adjuvant chemotherapy (AC), NAC regimen, and NAC cycle. We identified which factors influenced survival outcome and evaluated the prognostic role of these factors by univariate and multivariate analyses. Univariate analysis showed that the 5-year DMFS, PFS, and OS of NPC patients with N0-N1 were superior to those of patients with N2-N3 (5year DMFS: $97.3 \%$ vs. $88.0 \%, P=0.001$; PFS: $91.0 \%$ vs. 
Table 1: Basic characteristic of 594 LA NPC patients between 2 cycles and 3 to 4 cycles of NAC

\begin{tabular}{|c|c|c|c|c|}
\hline \multirow{2}{*}{ Characteristic } & 2 cycles of NAC & 3 to 4 cycles of NAC & \multirow{2}{*}{$\chi^{2}$} & \multirow{2}{*}{$P$} \\
\hline & No (\%) & No $(\%)$ & & \\
\hline Sex & & & 0.368 & 0.544 \\
\hline Male & $200(68.0)$ & $192(64.6)$ & & \\
\hline Female & $97(32.0)$ & $105(35.4)$ & & \\
\hline Age (years) & & & 0.013 & 0.910 \\
\hline Range & $19-77$ & $18-74$ & & \\
\hline Median & 49 & 50 & & \\
\hline$<60$ & $252(85.7)$ & $250((84.2)$ & & \\
\hline$\geq 60$ & $45(14.3)$ & $47(15.8)$ & & \\
\hline WHO pathology & & & 0.739 & 0.691 \\
\hline I & $6(2.0)$ & $4(1.3)$ & & \\
\hline II & $12(4.0)$ & $15(5.1)$ & & \\
\hline III & $278(94.0)$ & $277(93.4)$ & & \\
\hline T stage* & & & 1.772 & 0.621 \\
\hline $\mathrm{T} 1$ & $13(4.4)$ & $19(6.4)$ & & \\
\hline $\mathrm{T} 2$ & $72(24.2)$ & $67(22.6)$ & & \\
\hline $\mathrm{T} 3$ & $134(45.1)$ & $140(47.1)$ & & \\
\hline $\mathrm{T} 4$ & $78(26.3)$ & $71(23.9)$ & & \\
\hline N stage* & & & 2.403 & 0.493 \\
\hline No & $29(9.8)$ & $21(7.1)$ & & \\
\hline N1 & $71(23.9)$ & $67(22.6)$ & & \\
\hline $\mathrm{N} 2$ & $143(48.1)$ & $159(53.5)$ & & \\
\hline N3 & $54(18.2)$ & $50(16.8)$ & & \\
\hline Clinical stage* & & & 2.343 & 0.126 \\
\hline III & $197(66.3)$ & $178(59.9)$ & & \\
\hline IVA-B & $100(33.7)$ & $119(41.1)$ & & \\
\hline NAC regimen & & & 1.473 & 0.689 \\
\hline $\mathrm{TPF}$ & $83(35.0)$ & $85(51.3) /(103)$ & & \\
\hline $\mathrm{TP}$ & $104(26.7)$ & $92(13.1) /(152)$ & & \\
\hline GP & $57(3.3)$ & $58(2.0) /(68)$ & & \\
\hline $\mathrm{PF}$ & $53(35.0)$ & $62(33.6) /(73)$ & & \\
\hline $\mathrm{AC}$ & & & 146.081 & $<0.001$ \\
\hline No & $104(35.3)$ & $251(84.5)$ & & \\
\hline Yes & $193(64.7)$ & $48(15.5)$ & & \\
\hline WRT (day) ${ }^{\#}$ & & & & 0.04 \\
\hline Range & $30-104$ & $49-206$ & & \\
\hline Median & 49 & 82 & & \\
\hline
\end{tabular}

WHO, World Health Organization; AC, adjuvant chemotherapy; NAC, neoadjuvant chemotherapy; WRT, waiting time of radiotherapy.

${ }^{*}$ The 7 th AJCC/UICC staging system. ${ }^{*}$ t-test. 
$82.5 \%, P=0.012$; OS: $97.7 \%$ vs. $91.3 \%, P=0.008$ ), and the prognostic difference of DMFS and PFS was found between 2 cycles and 3 to 4 cycles of NAC (Table 3 ).

Consistent with the results of univariate analysis, 2 cycles of NAC improved PFS (hazard ratio [HR], 0.585; 95\% confidence interval [CI], 0.344-0.997; $P=0,049)$ and DMFS (HR, 0.499; 95\% CI, 0.258-0.964; $P=0,038$ ) (Table 4).

\section{Subgroup analysis}

We found that $\mathrm{N}$ category was an independent negative prognostic factor. Moreover, 5-year survival outcomes in NPC patients with N0-N1 were superior to those in patients with N2-N3. Therefore, we preformed the subgroup analysis to assess the prognostic value of NAC cycle in NPC patients according to N category. In NPC patients in the N0-N1 category, the 5-year LRRFS (93.3\% vs. $91.1 \%$, respectively; $P=0.751$ [Figure $3 \mathrm{~A}$ ]), DMFS (98.7\% vs. 96.4\%, respectively; $P=0.423$ [Figure 3B]), PFS (93.3\% vs. $89.3 \%$, respectively; $P=0.469$ [Figure $3 \mathrm{C}])$, and OS (98.7\% vs. $96.9 \%$, respectively; $P=0.598$ [Figure 3D]) were comparable between 2 cycles and 3 to 4 cycles of NAC.
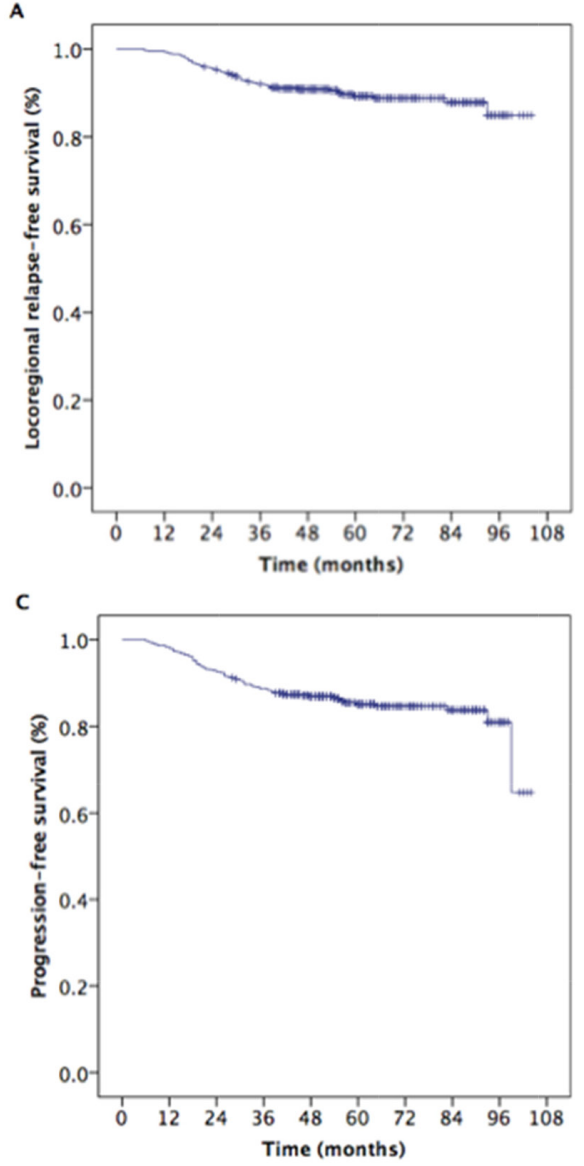

Likewise, for patients in the N2-N3 category, the 5 -year DMFS (91.4\% vs. $83.9 \%$, respectively; $P=0.019$ [Figure 4B]) and PFS (87.0\% vs. $77.2 \%$, respectively; $P$ $=0.019$ [Figure $4 \mathrm{C}$ ]) rates in patients receiving 2 cycles of NAC were higher than those in patients receiving 3 to 4 cycles of NAC, and the differences of 5-year LRRFS (90.6\% vs. $84.9 \%$, respectively; $P=0.091$ [Figure 4A]) and OS (92.4\% vs. $90.0 \%$, respectively; $P=0.170$ [Figure 4D]) between the two groups did not reach statistical significance.

\section{DISCUSSION}

This study revealed the impact of NAC cycle on survival outcomes in NPC patients by use of PSM and long follow-up time, and the results showed that 5-year DMFS and PFS in NPC patients receiving 2 cycles of NAC were higher than in NPC patients receiving 3 to 4 cycles of NAC. In addition, subgroup analysis demonstrated that adding more than 2 cycles of NAC to CCRT was associated with poor DMFS and PFS. Accordingly, we can draw a conclusion that 2 cycles of NAC might be enough and additional cycles are not associated with survival benefit for locoregionally advanced NPC.

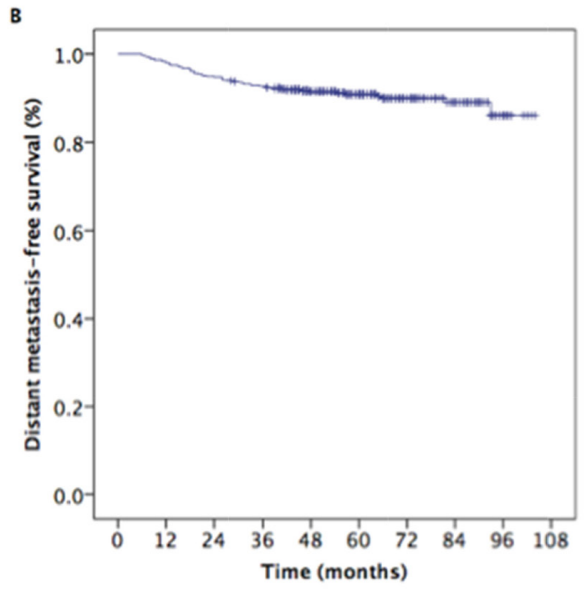

D

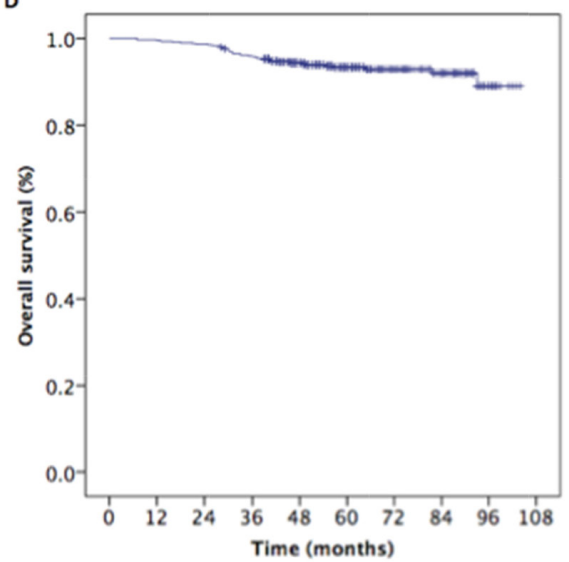

Figure 1: Kaplan-Meier estimates of the survival in 594 patients with nasopharyngeal carcinoma. 
A randomized phase III study showed that 3 cycles of TPF IC before CCRT improve survival outcomes, with 3-year OS of $92 \%$, 3-year FFS of $80 \%$, and 3-year DMFS of $90 \%$ [15]. In a randomized phase II trial by Hui et al. [21], 2 cycles of TP IC before CRT improved 3 -year OS compared with CRT alone (94.1\% vs. $67.7 \%$, $P=0.0112$ ). Kong et al. [16] reported that the 3-year PFS, DMFS, LRFS, and OS in patients with N3 disease were $81.8 \%, 81.8 \%, 100 \%$, and $90.9 \%$, respectively, after 4 cycles of NAC before CCRT. Thus, 2 cycles to 4 cycles of NAC have been widely used in clinical practice for locoregionally advanced NPC and improved survival outcomes of these patients. More NAC cycles could prolong the wait time of IMRT. In the current study, the median wait times were 49 days and 82 days, respectively, and a statistically significant difference was seen between 2 cycles and 3 to 4 cycles of NAC $(P=0.040)$.

The wait time of IMRT was the interval time between cancer diagnosis and radical IMRT. Generally, cancer patients should receive radical treatment as early as
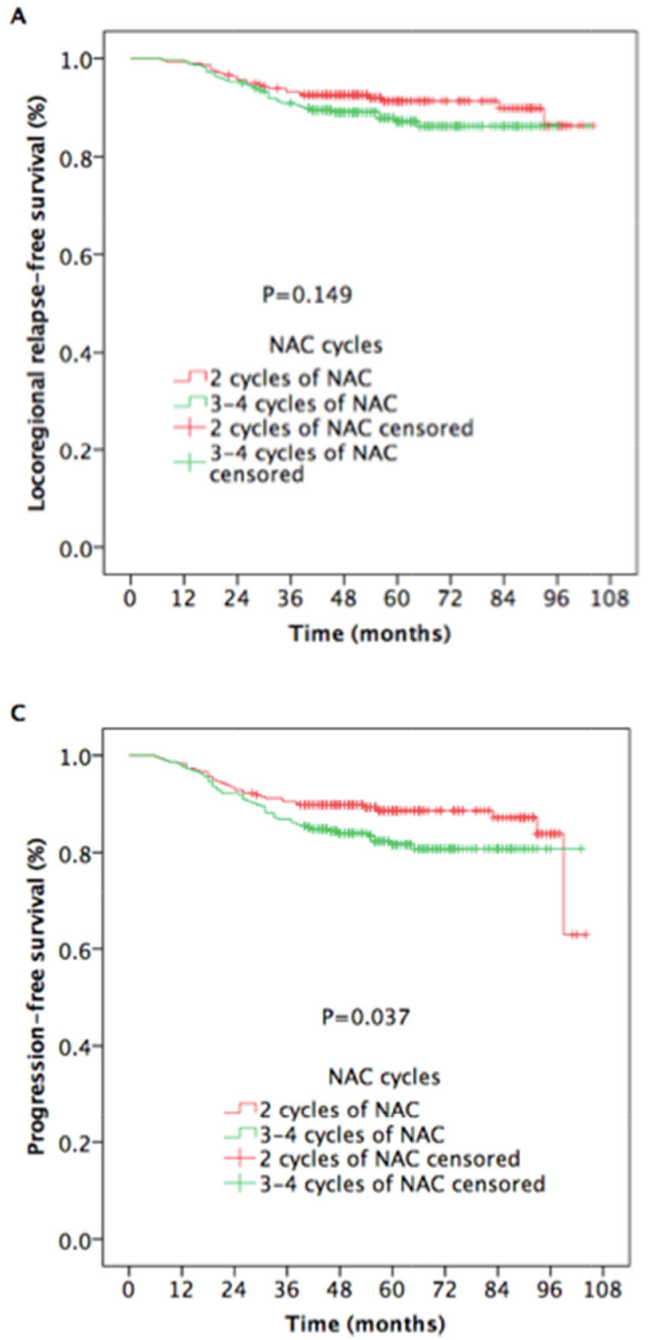

possible after they are diagnosed. However, many patients were hindered in receiving timely treatment because of social factors, limited medical resources, scarcity of policy support, and treatment-related factors [22]. Unfortunately, a correlation between long wait time and poor survival outcome was found in many cancers, including breast cancer, rectal cancer, bladder cancer, and head-and-neck cancer [23-26]. Chen et al. [18] showed that a longer wait time beyond 4 weeks was associated with worse PFS, but not worse OS, in 814 NPC patients with a short-term follow-up. Another study with a large population and long follow-up revealed a correlation between prolonged wait times more than 30 days and poor survival outcome [19]. From the above two studies, we determined the influence of wait time on the survival outcome for NPC. NAC is a primary factor in longer wait time even though it has been shown to improve survival outcomes in locoregionally advanced NPC. The wait time for patients who received $\geq 2$ cycles of NAC was more than 30 days. Thus, longer wait time reduces survival benefits of NAC in patients

B

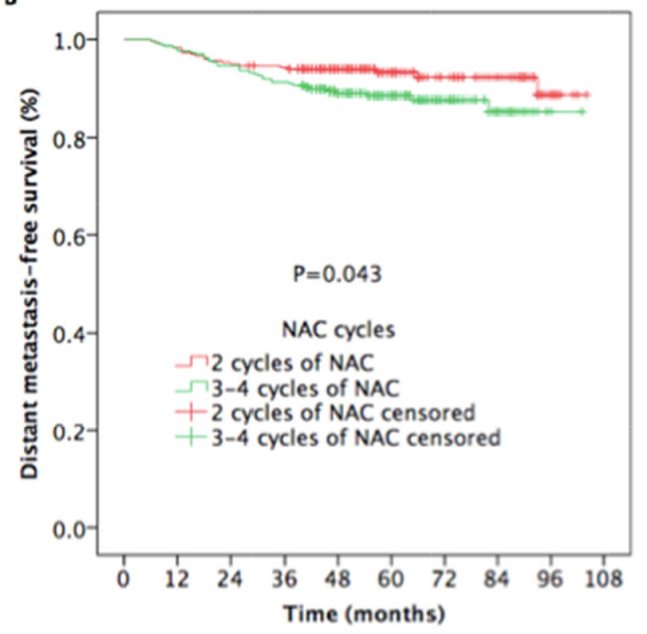

D

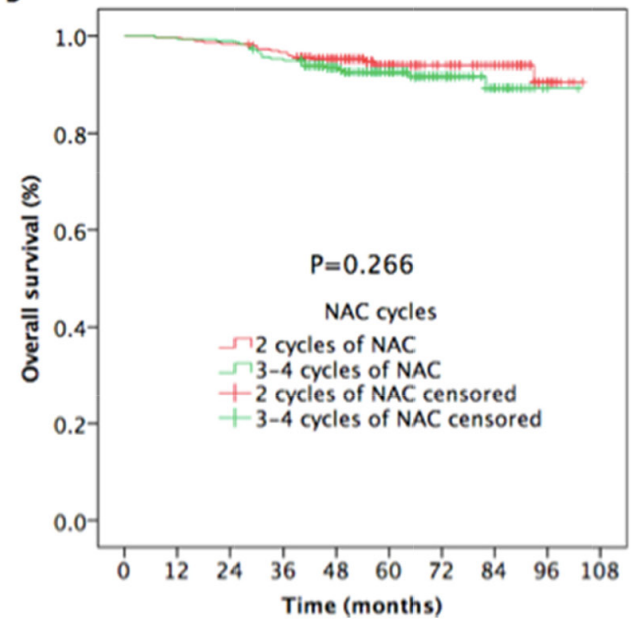

Figure 2: Kaplan-Meier estimates of the survival outcomes in nasopharyngeal carcinoma patients receiving 2 cycles and 3 to 4 cycles of NAC. 
Table 2: Treatment failure

\begin{tabular}{|c|c|c|c|}
\hline \multirow{2}{*}{ Failure mode } & 2 cycles of NAC & 3 to 4 cycles of NAC & \multirow{2}{*}{$\boldsymbol{P}$} \\
\hline & $\mathbf{N}=\mathbf{2 9 7}$ & $\mathbf{N}=\mathbf{2 9 7}$ & \\
\hline Locoregional & 14 & 18 & 0.218 \\
\hline Locoregional and distant & 12 & 17 & \\
\hline Distant & 9 & 17 & \\
\hline Nonfailure & 262 & 245 & \\
\hline
\end{tabular}

NAC, neoadjuvant chemotherapy.

Table 3: Prognostic factors on survival outcomes of 594 NPC patients by use of univariate analysis

\begin{tabular}{|c|c|c|c|c|c|c|c|c|}
\hline Characteristics & LRRFS (\%) & $P$ & DMFS (\%) & $P$ & PFS (\%) & $\bar{P}$ & OS (\%) & $P$ \\
\hline Sex & & 0.832 & & 0.088 & & 0.263 & & 0.050 \\
\hline Male & 89.3 & & 89.1 & & 84.0 & & 91.7 & \\
\hline Female & 89.1 & & 94.6 & & 87.5 & & 96.7 & \\
\hline Age & & 0.164 & & 0.824 & & 0.737 & & 0.061 \\
\hline$<60$ & 89.7 & & 91.0 & & 85.0 & & 94.2 & \\
\hline$\geq 60$ & 86.9 & & 90.2 & & 85.8 & & 88.5 & \\
\hline T stage & & 0.851 & & 0.937 & & 0.686 & & 0.948 \\
\hline $\mathrm{T} 1-\mathrm{T} 2$ & 89.6 & & 91.1 & & 84.0 & & 93.0 & \\
\hline $\mathrm{T} 3-\mathrm{T} 4$ & 89.2 & & 90.9 & & 85.4 & & 93.8 & \\
\hline $\mathrm{N}$ stage & & 0.192 & & 0.001 & & 0.012 & & 0.008 \\
\hline N0-N1 & 92.0 & & 97.3 & & 91.0 & & 97.7 & \\
\hline N2-N3 & 88.4 & & 88.0 & & 82.5 & & 91.3 & \\
\hline Clinical stage & & 0.111 & & 0.004 & & 0.016 & & 0.008 \\
\hline III & 90.5 & & 93.5 & & 87.3 & & 95.6 & \\
\hline IVA/B & 87.2 & & 86.4 & & 81.4 & & 89.4 & \\
\hline $\mathrm{AC}$ & & 0.225 & & 0.735 & & 0.707 & & 0.330 \\
\hline Yes & 88.0 & & 90.4 & & 84.6 & & 96.2 & \\
\hline No & 91.6 & & 91.6 & & 86.1 & & 92.7 & \\
\hline NAC regimen & & 0.450 & & 0.850 & & 0.662 & & 0.945 \\
\hline TPF & 88.2 & & 91.6 & & 83.9 & & 93.6 & \\
\hline TP & 91.7 & & 91.2 & & 87.5 & & 92.5 & \\
\hline GP & 93.8 & & 91.8 & & 89.8 & & 95.9 & \\
\hline FP & 86.2 & & 88.5 & & 82.6 & & 92.7 & \\
\hline NAC cycle & & 0.149 & & 0.043 & & 0.037 & & 0.266 \\
\hline 2 cycles & 91.3 & & 93.3 & & 88.7 & & 94.0 & \\
\hline 3 to 4 cycles & 87.2 & & 88.5 & & 81.7 & & 92.6 & \\
\hline
\end{tabular}

LRRFS, locoregional relapse-free survival; DMFS, distant metastases-free survival; PFS, progression-free survival; OS, overall survival; AC, adjuvant chemotherapy; NAC, neoadjuvant chemotherapy; TP, docetaxel/cisplatin; TPF, docetaxel/ cisplatin/fluorouracil; GP, gemcitabine/cisplatin; FP, cisplatin/fluorouracil. 
Table 4: Multivariate analysis of prognostic factors in 594 LA NPC patients

\begin{tabular}{|c|c|c|c|c|c|}
\hline Endpoint & Variate & Category & HR & $95 \% \mathrm{CI}$ & $P$-value \\
\hline \multirow[t]{3}{*}{ OS } & NAC cycle & 2 cycles vs. 3 to 4 cycles & 0.695 & $0.323-1.498$ & 0.353 \\
\hline & Age & $<60$ vs. $\geq 60$ years & 0.451 & $0.209-0.973$ & 0.042 \\
\hline & N stage* & N0-N1 vs. N2-N3 & 0.272 & $0.105-0.707$ & 0.008 \\
\hline \multirow[t]{2}{*}{ PFS } & NAC cycle & 2 cycles vs. 3 to 4 cycles & 0.585 & $0.344-0.997$ & 0.049 \\
\hline & N stage* & N0-N1 vs. N2-N3 & 0.483 & $0.280-0.834$ & 0.009 \\
\hline LRRFS & NAC cycle & 2 cycles vs. 3 to 4 cycles & 0.820 & $0.459-1.532$ & 0.535 \\
\hline \multirow[t]{2}{*}{ DMFS } & NAC cycle & 2 cycles vs. 3 to 4 cycles & 0.499 & $0.258-0.964$ & 0.038 \\
\hline & N stage* & N0-N1 vs. N2-N3 & 0.239 & $0.101-0.565$ & 0.001 \\
\hline
\end{tabular}

OS, overall survival; PFS, progression-free survival; LRRFS, locoregional recurrence-free survival; DMFS, distant metastasis-free survival; NAC, neoadjuvant chemotherapy.

*The 7 th AJCC/UICC staging system.

A

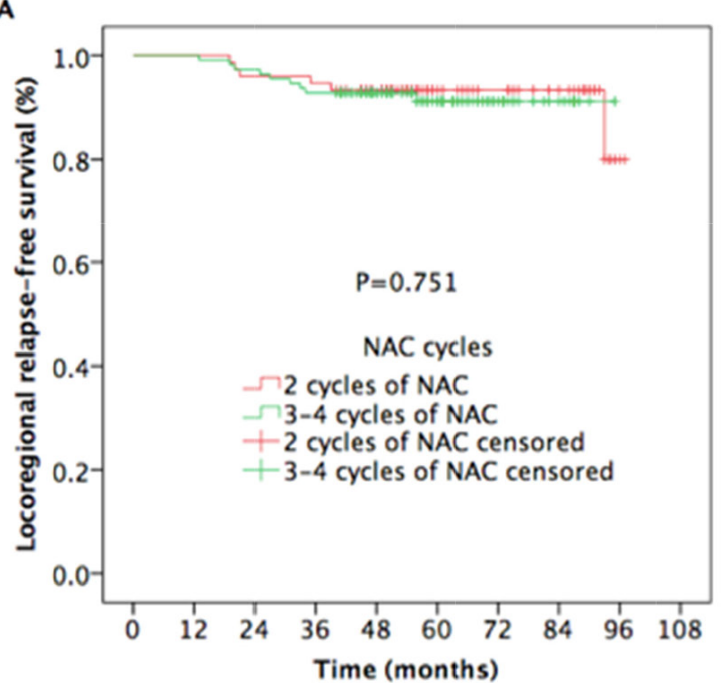

C

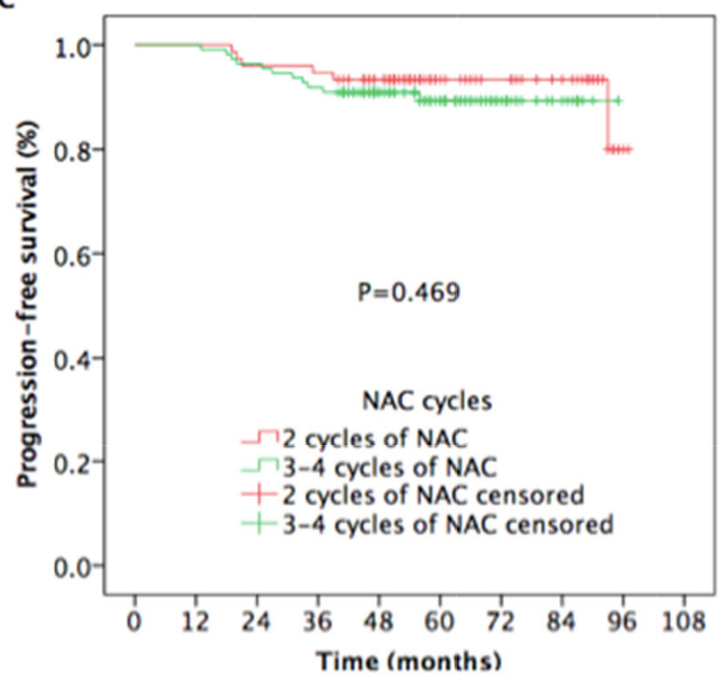

B

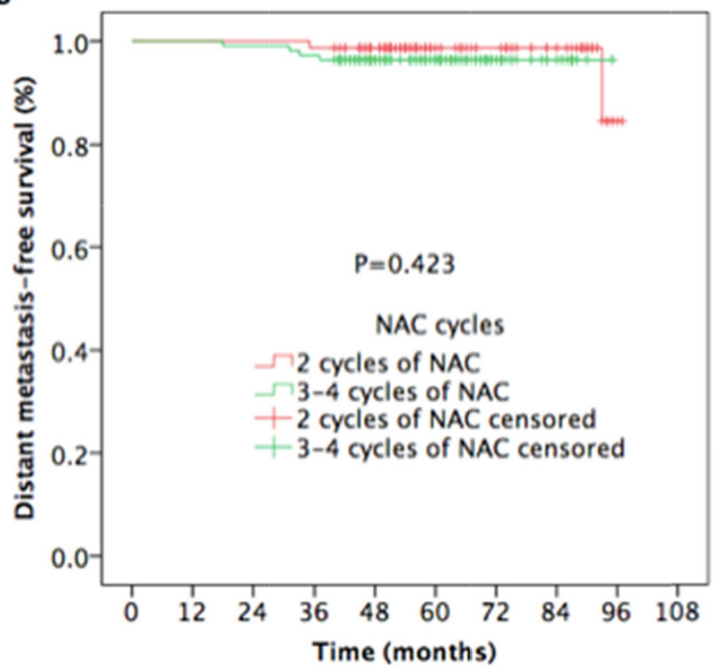

D

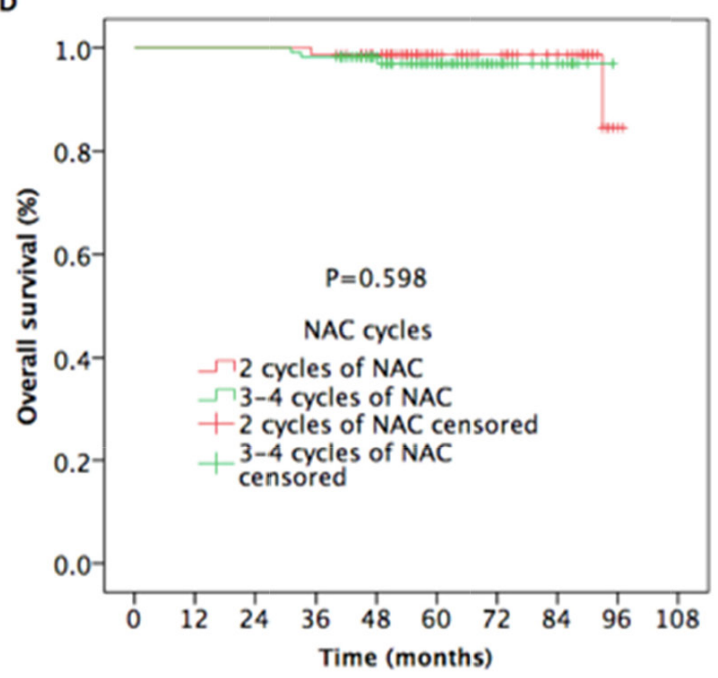

Figure 3: Kaplan-Meier estimates of survival outcomes in nasopharyngeal carcinoma patients with N0-N1 receiving 2 cycles and 3 to 4 cycles of NAC. 
with locoregionally advanced NPC. So, we recommend $\geq 2$ cycles of NAC as optimal before timely IMRT for locoregionally advanced NPC. A study by Peng et al. [27], with 247 pairs of NPC patients, including limited clinical characteristics, found no significantly prognostic difference between 2 cycles and $>2$ cycles of NAC, but stratified analysis demonstrated that patients receiving 2 cycles of NAC had better OS than patients receiving $>2$ cycles, and NAC was an independent prognostic factor of OS for the N2-N3 category. However, in the study, the wait time was not tested between the two groups. Consequently, $>2$ cycles of NAC were not proved to be associated with worse survival outcomes, although a statistically significant difference for N2-N3 between the two groups was seen.

In the current study, on the basis of long follow-up times, 5-year LRRFS, DMFS, PFS, and OS rates between
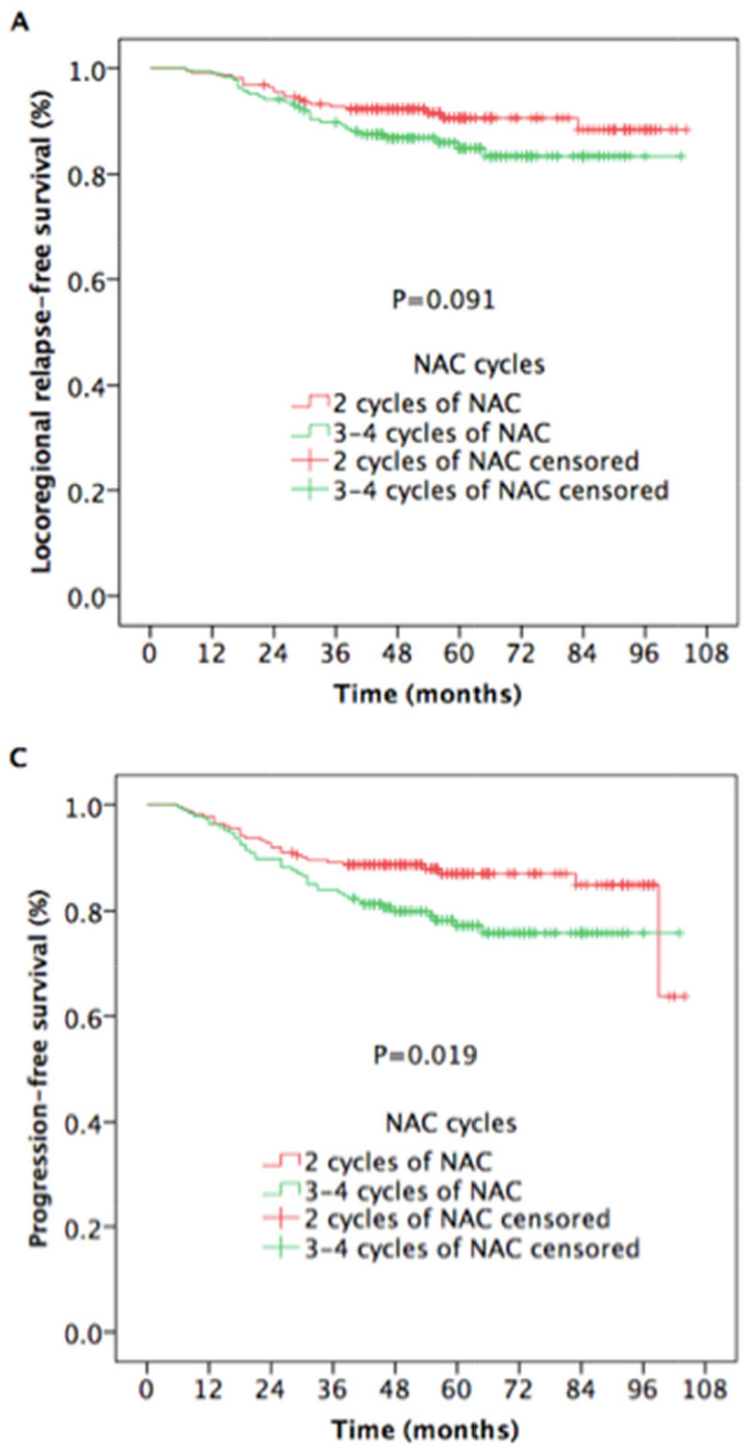

two groups were $91.3 \%, 93.3 \%, 88.7 \%$, and $94.0 \%$ and $87.2 \%, 88.5 \%, 81.7 \%$, and $92.6 \%$, respectively. However, statistically significant differences in DMFS and PFS were seen between the two groups. We identified which factors influenced survival outcome and evaluated the prognostic role of these factors by univariate and multivariate analyses. We found that $\mathrm{N}$ category was an independent prognostic factor of LRRFS, DMFS, PFS, and OS, and NAC cycle was an independent predictor of DMFS and PFS.

We used PSM and multivariate analysis to assess the prognostic role of NAC cycle for locoregionally advanced NPC. Our study has some limitations because of the retrospective nature, single center, and heterogeneous NAC regimens. Further prospective trails are warranted.

We found that $>2$ cycles of NAC before CCRT resulted in better DMFS and PFS in patients with

B

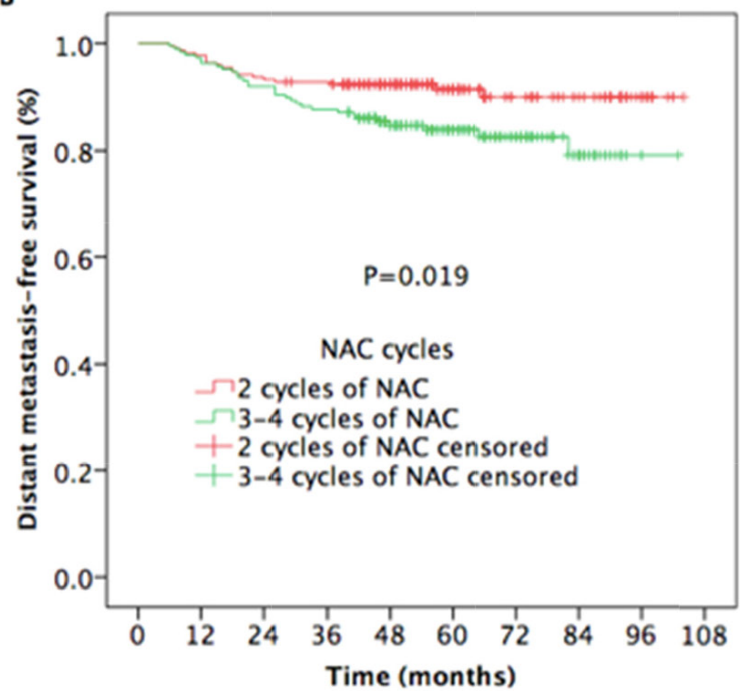

D

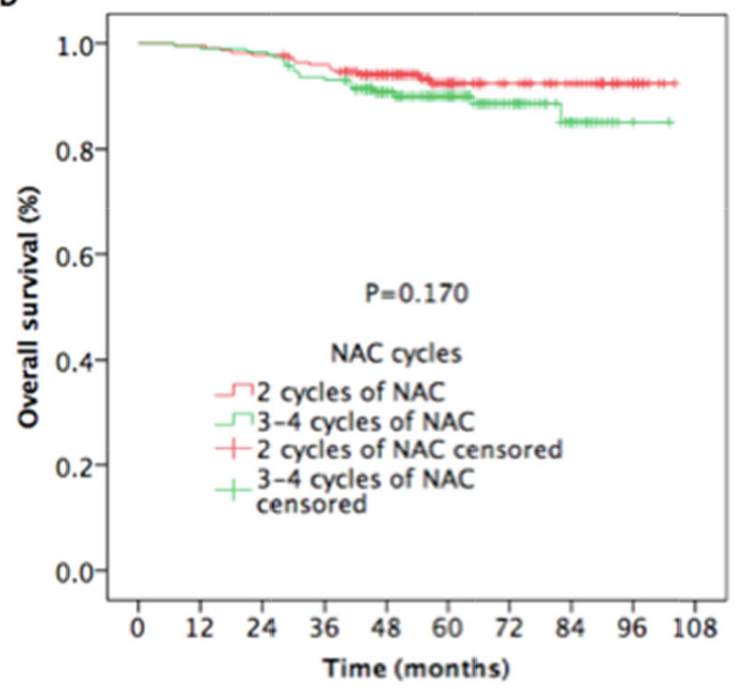

Figure 4: Kaplan-Meier estimates of survival outcomes in N2-N3 nasopharyngeal carcinoma patients receiving 2 cycles and 3 to 4 cycles of NAC. 
locoregionally advanced NPC. However, because of the retrospective nature of the study, our results should be regarded as preliminary.

\section{MATERIALS AND METHODS}

\section{Patients}

The patients enrolled in this study were hospitalized from May 2008 to April 2014 in the Department of Radiation Oncology, Zhejiang Cancer Hospital. The eligible patients met the following criteria: (i) histologically proved locoregionally advanced NPC, (ii) Eastern Cooperative Oncology Group performance status $\leq 1$, (iii) completion of radical IMRT, (iv) received 2 to 4 cycles of NAC before CCRT, and (v) received no previous anti-cancer treatment. Of 1,188 patients, 594 (50.0\%) were matched for the current study. This retrospective study was approved by the Medical Ethics Committee of Zhejiang Cancer Hospital. All the patients signed informed consent forms.

\section{Baseline examinations}

Patients had pretreatment evaluations that included complete histories, physical examinations, hematology and biochemistry profiles, chest radiographs, sonography of the abdomen, bone scans, magnetic response images of the nasopharynx, and nasopharyngoscopies. All patients were staged according to the 2010 American Joint Committee on Cancer staging system. Tumor histology was classified per the World Health Organization classification.

\section{Intensity-modulated radiotherapy}

All patients underwent radical IMRT with simultaneous integrated boost technique that utilized 6-MV photons 2 to 3 weeks after IC. The delineation of target volumes of NPC during the treatment of IMRT was described previously [28-31]. Gross tumor volumes (GTVs) of primary tumor and the metastatic lymph nodes were defined as GTVnx and GTVnd, which were delineated according to pre-IC and post-IC MR images, respectively. The clinical target volume of nasopharynx (CTVnx) was defined as GTVnx plus a 7-mm margin that encompassed the nasopharyngeal mucosa plus $5-\mathrm{mm}$ submucosal volume. The high-risk clinical target volume (CTV1) included the entire nasopharyngeal cavity, the anterior one-third to two-thirds of the clivus, the skull base, the pterygoid plates, the parapharyngeal space, the inferior sphenoid sinus, the posterior one-quarter to onethird of the nasal cavity, and the maxillary sinus and any lymph nodes in drainage pathways containing metastatic lymph nodes. The low-risk clinical target volume (CTV2) included levels IV and $\mathrm{Vb}$ without metastatic cervical lymph nodes.
The PTV was constructed automatically on the basis of each volume with an additional 3-mm margin in three dimensions to account for set-up variability. All the PTVs, including PGTVnx, PTVnx, PTV1, and PTV2, were not delineated outside of the skin surface. Critical normal structures, including the brainstem, spinal cord, parotid glands, optic nerves, chiasm, lens, eyeballs, temporal lobes, temporomandibular joints, mandible, and hypophysis were contoured and set as OARs during optimization.

The prescribed radiation dose was 69 or 72 Gy to PGTVnx, 66-70 Gy to PGTVnd, 62 to 66 Gy to PTVnx, 60 to 63 Gy to PTV1, and 51 to 54 Gy to PTV2, delivered in 30 or 33 fractions. Radiation was delivered once daily, five fractions per week, over 6 to 6.5 weeks for IMRT planning. The dose to OAR was limited on the basis of the RTOG 0225 protocol.

\section{Chemotherapy}

All patients were given 2 to 4 cycles of platinumbased induction chemotherapy every 3 weeks. The available NAC regimens included TPF (docetaxel $60 \mathrm{mg}$ / $\mathrm{m}^{2} / \mathrm{d}$ on day 1 , cisplatin $25 \mathrm{mg} / \mathrm{m}^{2} / \mathrm{d}$ on days 1 to 3 , and 5 -fluorouracil $500 \mathrm{mg} / \mathrm{m}^{2} / \mathrm{d}$ on days 1 to 3 ), TP (docetaxel $60 \mathrm{mg} / \mathrm{m}^{2} / \mathrm{d}$ on day 1 and cisplatin $25 \mathrm{mg} / \mathrm{m}^{2} / \mathrm{d}$ on days 1 to 3), GP (gemcitabine $1,000 \mathrm{mg} / \mathrm{m}^{2} / \mathrm{d}$ on days 1 and 8 and cisplatin $25 \mathrm{mg} / \mathrm{m}^{2} / \mathrm{d}$ on days 1 to 3 ), and FP (cisplatin 25 $\mathrm{mg} / \mathrm{m}^{2} / \mathrm{d}$ on days 1 to 3 and 5 -fluorouracil $500 \mathrm{mg} / \mathrm{m}^{2} / \mathrm{d}$ on days 1 to 3 ).

The patients in this study underwent concurrent chemotherapy with cisplatin $\left(80 \mathrm{mg} / \mathrm{m}^{2}\right)$ divided into 3 doses administered in 3 days every 3 weeks for 2 to 3 cycles and received 21-day cycles of adjuvant chemotherapy with FP (cisplatin $25 \mathrm{mg} / \mathrm{m}^{2} / \mathrm{d}$ on days 1 to 3 , and 5-fluorouracil $500 \mathrm{mg} / \mathrm{m}^{2} / \mathrm{d}$ on days 1 to 3 ) or GP regimens within 3 to 4 weeks after RT.

\section{Efficacy evaluation and follow-up}

The assessment of tumor response was performed three times after the completion of IC, at the end of IMRT, and 3 months after irradiation, which was based on MRI and nasopharynx fiberscope per the Response Evaluation Criteria for Solid Tumors. Systemic chemotherapy adverse events were graded per the National Cancer Institute Common Toxicity Criteria (NCI CTCAE Version 3.0), and RT-induced toxicities were scored per the Acute and Late Radiation Morbidity Scoring Criteria of the Radiation Therapy Oncology Group.

All the subjects underwent weekly examinations for treatment response and toxicities during RT. Patients were followed every 3 months in the first 2 years, every 6 months from the third to the fifth year, and then annually. Each follow-up included careful examination of the nasopharynx and neck nodes by an experienced doctor. 
MRI scans of the nasopharynx, nasopharynx fiberscope, chest computed tomography radiograph, and ultrasound of abdomen were performed 3 months after the completion of RT and every 6 to 12 months thereafter. Additional examinations were performed when indicated to evaluate local relapse or distant metastasis.

\section{Statistical analysis}

The end points of this study included LRRFS, DMFS, PFS, OS, and acute toxicities from IC and CCRT. OS was calculated from the date of enrollment in the trail to the date of death or the last follow-up. LRRFS, DMFS, and PFS were calculated from the date of enrollment in the trail to the date of locoregional relapse, distant metastasis occurrence and the diagnosed evidence of disease progression, or the last follow-up, respectively. After recurrence or metastasis, patients were given salvage therapy as determined by their physicians.

Descriptive statistics were used to compare the patients' characteristics and patterns of failure between the two arms. Two independent sample non-parametric tests were used to compare the acute toxicity between the two arms. Survival curves were generated by application of the Kaplan-Meier method. The curves were compared by use of log-rank tests. Multivariate analysis was performed by use of Cox regression models to identify significant prognostic factors. HRs and 95\% CIs were calculated for each prognostic factor. IBM SPSS Statistics Version 19.0 was used for all data analysis. A $P<0.05$ was considered statistically significant.

\section{CONCLUSION}

We observed that an additional 2 cycles of NAC followed by CCRT might be enough and adding more cycles is not associated with survival benefit in locoregionally advanced NPC patients. Further randomized, controlled, multicenter phase III clinical trials are needed to confirm the therapeutic gain.

\section{CONFLICTS OF INTEREST}

The authors declare that there are no conflicts of interest.

\section{FUNDING}

This study was supported by grants from the Medical Science Foundation of Zhejiang Health Bureau (No. 2013KYB033, No. 2009B026, No. 2006A016, No. 2005B012, and No. 2004B014) and the National Natural Science Foundation of China (No. 81502646 and No. 81502647).

\section{REFERENCES}

1. Tang LL, Chen WQ, Xue WQ, He YQ, Zheng RS, Zeng YX, Jia WH. Global trends in incidence and mortality of nasopharyngeal carcinoma. Cancer Lett. 2016; 374: 22-30.

2. Chen L, Mao YP, Xie FY, Xie FY, Liu LZ, Sun Y, Tian L, Tang LL, Lin AH, Li L, Ma J. The seventh edition of UICC/AJCC staging system for nasopharyngeal carcinoma is prognostically useful for patients treated with intensitymodulated radiotherapy from an endemic area in China. Radiother Oncol. 2012; 104:331-337.

3. Wee J. Nasopharyngeal carcinoma: a promising future. Lancet Oncol. 2012; 13:116-118.

4. Lai SZ, Li WF, Chen L, Luo W, Chen YY, Liu LZ, Sun Y, Lin AH, Liu MZ, Ma J. How does intensity modulated radiotherapy versus conventional twodimensional radiotherapy influence the treatment results in nasopharyngeal carcinoma patients? Int J Radiat Oncol Biol Phys. 2011; 80:661-668.

5. Al-Sarraf M, Reddy MS. Nasopharyngeal carcinoma. Curr Treat Options Oncol. 2002; 3:21-32.

6. Al-Sarraf M, LeBlanc M, Giri PG, Fu KK, Cooper J, Vuong T, Forastiere AA, Adams G, Sakr WA, Schuller DE, Ensley JF. Chemoradiotherapy versus radiotherapy in patients with advanced nasopharyngeal cancer: phase III randomized Intergroup study 0099. J Clin Oncol. 1998; 16:1310-1317.

7. Lee AW, Tung SY, Chua DT, Ngan RK, Chappell R, Tung R, Siu L, Ng WT, Sze WK, Au GK, Law SC, O'Sullivan $\mathrm{B}$, Yau TK, et al. Randomized trial of radiotherapy plus concurrent-adjuvant chemotherapy vs radiotherapy alone for regionally advanced nasopharyngeal carcinoma. J Natl Cancer Inst. 2010; 102:1188-1198.

8. Baujat B, Audry H, Bourhis J, Chan AT, Onat H, Chua DT, Kwong DL, Al-Sarraf M, Chi KH, Hareyama M, Leung SF, Thephamongkhol K, Pignon JP. Chemotherapy in locally advanced nasopharyngeal carcinoma: an individual patient data meta-analysis of eight randomized trials and 1753 patients. Int J Radiat Oncol Biol Phys. 2006; 64:47-56.

9. OuYang PY, Xie C, Mao YP, Zhang Y, Liang XX, Su Z, Liu Q, Xie FY. Significant efficacies of neoadjuvant chemotherapy and adjuvant chemotherapy for nasopharyngeal carcinoma by meta-analysis of published literature-based randomized, control trials. Ann Oncol. 2013, 24:2136-2146.

10. Chen YP, Guo R, Liu N, Liu X, Mao YP, Tang LL, Zhou GQ, Lin AH, Sun Y, Ma J. Efficacy of the additional neoadjuvant chemotherapy to concurrent chemoradiotherapy for patients with locoregionally advanced nasopharyngeal carcinoma: a Bayesian network meta-analysis of randomized controlled trials. J Cancer. 2015; 6:883-892.

11. Wang MM, Tian HM, Li G, Ge T, Liu Y, Cui J, Han F. Significant benefits of adding neoadjuvant chemotherapy 
before chemoradiotherapy for locoregionally advanced nasopharyngeal carcinoma: a meta-analysis of randomized controlled trials. Oncotarget. 2016; 7:48375-390. https:// doi.org/10.18632/oncotarget.10237.

12. Hui EP, Ma BB, Leung SF, King AD, Mo F, Kam MK, Yu BK, Chiu SK, Kwan WH, Ho R, Chan I, Ahuja AT, Zee $\mathrm{BC}$, et al. Randomized phase II trial of concurrent cisplatinradiotherapy with or without neoadjuvant docetaxel and cisplatin in advanced nasopharyngeal carcinoma. J Clin Oncol. 2009; 27:242-249.

13. Fountzilas G, Cluleanun E, Bobos M, Kalogera-Fountzila A, Eleftheraki AG, Karayannopoulou G, Zaramboukas T, Nikolaou A, Markou K, Resiga L, Dionysopoulos D, Samantas E, Athanassiou H, et al. Induction chemotherapy followed by concomitant radiotherapy and weekly cisplatin versus the same concomitant chemoradiotherapy in patents with nasopharyngeal carcinoma: a randomized phase II study conducted by the Hellenic Cooperative Oncology Group (HeCOG) with biomarker evaluation. Ann Oncol. 2012; 23:427-435.

14. Huang PY, Cao X, Mo HY, Mo HY, Guo L, Xiang YQ, Deng MQ, Qiu F, Cao SM, Guo Y, Zhang L, Li NW, Sun $\mathrm{R}$, et al. A randomized trial of induction chemotherapy plus concurrent chemotherapy versus induction chemotherapy plus radiotherapy for locoregionally advanced nasopharyngeal carcinoma. Oral Oncol. 2012; 48:1034-1044.

15. Sun Y, Li WF, Chen NY, Zhang N, Hu GQ, Xie FY, Sun Y, Chen XZ, Li JG, Zhu XD, Hu CS, Xu XY, Chen $\mathrm{YY}$, et al. Induction chemotherapy plus concurrent chemotherapy versus concurrent chemoradiotherapy alone in locoregionally advanced nasopharyngeal carcinoma: a phase 3, multicentre, randomized controlled trial. Lancet Oncol. 2016; 12:1509-1520.

16. Kong L, Zhang YW, Hu CS, Guo Y, Lu JJ. Effects of induction docetaxel, platinum, and fluorouracil chemotherapy in patients with stage III or IVA/B nasopharyngeal cancer treated with concurrent chemoradiation therapy: final results of 2 parallel phase clinical trial. Cancer. 2017; 123:2258-2267.

17. Zhang Y, Chen M, Chen C, Kong L, Lu JJ, Xu B. The efficacy and toxicities of intensive induction chemotherapy followed by concurrent chemotherapy in nasopharyngeal carcinoma patients with N3 disease. Sci Rep. 2017; 7:3668.

18. Chen YP, Mao YP, Zhang WN, Chen L, Tang LL, Li WF, Liu X, Zhou GQ, Sun Y, Kang TB, Zeng MS, Ma J. Prognostic value of wait time in nasopharyngeal carcinoma treated with intensity modulated radiotherapy: a propensity matched analysis. Oncotarget. 2016; 7:14973-14982. https://doi.org/10.18632/oncotarget.7789.

19. Liang H, Xiang YQ, Lu X, Xie CQ, Cao SM, Wang L, Qian CN, Yang J, Ye YF, Gan F, Ke LR, Yu YH, Liu GY, et al. Survival impact of waiting time for radical radiotherapy in nasopharyngeal carcinoma: a large institution-based cohort study from an endemic area. Eur J Cancer. 2017; 73: 48-60.

20. Austin PC. The relative ability of different propensity score methods to balance measured covariates between treated and untreated subjects in observational studies. Med Decis Making. 2009; 29:661-677.

21. Hui EP, Ma BB, Leung SF, Kang AD, Mo F, Kam MK, Yu BK, Chiu SK, Kwan WH, Ho R, Chan I, Ahuja AT, Zee $\mathrm{BC}$, et al. Randomized phase II trial of concurrent cisplatinradiotherapy with or without neoadjuvant docetaxel and cisplatin in advanced nasopharyngeal carcinoma. J Clin Oncol. 2009; 27:242-9.

22. Atun R, Jaffray DA, Barton MB, Bray F, Baumann M, Vikram B, Hanna TP, Knaul FM, Lievens Y, Liu TY, Milosevic M, O’Sullivan B, Rodin DL, et al. Expanding global access to radiotherapy. Lancet Oncol. 2015; 16:1153-1186.

23. Richards MA, Westcombe AM, Love SB, Littlejohns P, Ramirez AJ. Influence of delay on survival in patients with breast cancer: a systematic review. Lancet. 1999; 353:1119-1126.

24. Yun YH, Kim YA, Min YH, Park S, Won YJ, Kim DY, Choi IJ, Kim YW, Park SJ, Kim JH, Lee DH, Yoon SJ, Jeong SY, et al. The influence of hospital volume and surgical treatment delay on long-term survival after cancer surgery. Ann Oncol. 2012; 23:2731-2737.

25. Kukarni GS, Urbacn DR, Austin PC, Fleshner NE, Laupacis A. Longer wait time increase overall mortality in patients with bladder cancer. J Urol. 2009; 182:1318-1324.

26. Chen Z, King W, Pearcey R, Kerba M, Mackillop WJ. The relationship between waiting time for radiotherapy and clinical outcomes: a systematic review of the literature. Radiother Oncol. 2008; 87:3-16.

27. Peng H, Chen L, Li WF, Zhang Y, Liu LZ, Tian L, Lin AH, Sun Y, Ma J. Optimized the cycle of neoadjuvant chemotherapy for locoregionally advanced nasopharyngeal carcinoma treated with intensity-modulated radiotherapy: a propensity score matching analysis. Oral Oncol. 2016; 62:78-84.

28. Wang F, Jiang C, Wang L, Yan F, Ye Z, Sun Q, Liu $\mathrm{T}, \mathrm{Xu} \mathrm{M}, \mathrm{Wu} \mathrm{P}$, Long B, Rihito A, Masoto S, Fu Z. Addition of 5-fluorouracil to first-line induction chemotherapy with docetaxel and cisplatin before concurrent chemoradiotherapy does not improve survival in locoregionally advanced nasopharyngeal carcinoma. Oncotarget. 2017; 8:91150-91161. https://doi.org/10.18632/ oncotarget.20017.

29. Wang FZ, Sun QQ, Jiang CE, Wang L, Yan FQ, Ye ZM, Liu TX, Xu M, Wu P, Jiang HT, Rihito A, Masoto S, Wang $\mathrm{YZ}$, et al. Gemcitabine/cisplatin induction chemotherapy before concurrent chemotherapy and intensity-modulated radiotherapy improves outcomes for locoregionally advanced nasopharyngeal carcinoma. Oncotarget. 2017 
May 27. https://doi.org/10.18632/oncotarget.18245. [Epub ahead of print].

30. Wang FZ, Jiang CE, Ye ZM, Sun QQ, Liu TX, Xu M, Wu P, Shi KY, Long B, Rihito A, Masoto S, Fu ZF. Efficacy and safety of nimotuzumab with neoadjuvant chemotherapy followed by concurrent chemoradiotherapy for locoregionally advanced nasopharyngeal carcinoma.
Oncotarget. 2017; 8:75544-75556. https://doi.org/10.18632/ oncotarget.17357.

31. Wang FZ, Jiang CE, Wang L, Chen WJ, Xu M, Sun QQ, Liu TX, Aizawa R, Sakamoto M, Fu ZF. Outcome and long-term efficacy of four facio-cervical fields conformal radiotherapy for nasopharyngeal carcinoma. Oncotarget. 2017; 8:3975639765. https://doi.org/10.18632/oncotarget.14403. 